Volume 18 Issue 1 April 2020, pages:166-174

\title{
Aspek-Aspek Arsitektur Kolonial Belanda Pada Bangunan Pendopo Puri Mangkunegaran Surakarta
}

\section{The Aspects of Dutch Colonial Architecture in the Building of "Pendopo Puri Mangkunegaran Surakarta"}

\author{
Samsudi $^{1}$ *, Agung Kumoro $W^{2}$, Dyah Susilowati Pradnya $P^{3}$, Anita Dianingrum ${ }^{4}$ \\ Architecture Department, Faculty of Engineering, Universitas Sebelas Maret ${ }^{1 *}$ \\ Email : samsudiarsi@yahoo.co.id \\ Architecture Department, Faculty of Engineering, Universitas Sebelas Maret ${ }^{2}$ \\ Architecture Department, Faculty of Engineering, Universitas Sebelas Maret ${ }^{3}$ \\ Architecture Department, Faculty of Engineering, Universitas Sebelas Maret ${ }^{4}$
}

DOI: https://doi.org/10.20961/arst.v18i1.40893

Received: March 26, 2020 Revised : April 29,2020 Accepted: April 29,2020 Available online: April 30,2020

\begin{abstract}
Dutch colonial architecture that developed in Indonesia, throughout the colonial period (around the $17^{\text {th }}$ century to 1942) was a combination of colonial and local culture to respond to the Indonesian climate. Dutch colonial architecture in Indonesia is a work of Dutch colonial heritage in Indonesia during the colonial period. The result was the Dutch East Indies style with a "colonial" image and adapted to the local environment that responded to climate. Colonial architecture grafted architecture from European countries into colonies. The aspects of Dutch colonial architecture in the "Pendopo Puri Mangkunegran" building were studied to find out the elements of Dutch colonial architecture. "Pendopo Puri Mangkunegarn" is a vernacular architecture / Javanese architecture with a pillar structure system, allegedly there is an architectural element from the outside due to acculturation. The results of this study will be encouraged to know aspects of Dutch colonial architecture in the "Pendopo Puri Mangkunegaran" building from aspects of floor plans, structures, materials and other architectural elements. The results of this study are also expected to contribute knowledge in the field of architecture related to acculturation of foreign cultures that have an impact on local architecture.
\end{abstract}

Keywords: Dutch architectural elements; structure; material

\section{PENDAHULUAN}

Awal Belanda datang di Indonesia pada Tahun 1596 di pelabuan Banten adalah untuk berdagang dengan nama dagang VOC (Vereeigde Oodst-Indische Compagnie) yang berdiri pada Tahun 1602. Lambat laun Belanda dapat menguasai Indonesia sebagai negara jajahan VOC yang berpusat di Ambon kemudian berpindah ke Jayakarta (Jakarta). Belanda membuat benteng VOC di Jayakarta dengan nama Batavia wilayah Perluasan Politik VOC, setelah di Batavia Belanda bergerak ke timur masuk ke daerah pesisir utara Pulau Jawa, masuk di Jawa-Tengah yaitu 
Tegal, Semarang, dan sekitarnya dan berhasil memperlemah Kerajaan Mataram dan masuk ke Surakarta.

Arsitektur Kolonial merupakan arsitektur yang dibawa bangsa Belanda dari negri Eropa ke daerah jajahan (koloni)(A.Bagus. P. W). Karya arsitektur peninggalan kolonial Belanda di Indonesia selama dalam waktu penjajahan (abad 17 sampai Tahun 1942), hasilnya berbentuk gaya Hindia-Belanda yang ber citra "kolonial" yang disesuaikan dengan lingkungan lokal serta merespon iklim (J.Hellen" Ductch Colonial Villa dalam Hadinoto).

\subsection{Sejarah Perpindahan Mataram}

Kepindahan Karaton Mataram dari Kartasura ke Surakarta, pada Tahun 1745 karena "geger pacinan" pada waktu pemerintahan Susuhunan Pakubuwono II di Sala. Perjanjian Giyanti (13 Maret 1755), terjadi "palihan" (oleh Kompeni) Mataram menjadi dua wilayah politik divide et empera (adu domba), 1). Kasunanan Surakarta di perintah Sri Susuhunan Pakubuwono I (Senopati Ing Ngalogo) dan 2). Kasultanan Yogyakarta di bawah Mangkubumi bergelar Sri sultan Hamengkubuwana I, perkembangan selanjutnya Karaton Yogyakarta di pecah menjadi dua bagian Kasultanan dan Pakualaman (di perintah Paku Alam I). Perjajian Salatiga pada Tahun 1757, Raden Mas Said (Pangeran Sambernyawa) mendirikan Istana bernama Puri Mangkunegaran (Mangkunegoro I), adanya Perjanjian Giyanti dan Perjanjian Salatiga Sejarah Pemerintahan Puri Mangkunagaran berdiri Tahun 1757 yang diperintah oleh Mangkunegara I (R.M Said) (1957-1996) yang pada awal berada di Kethelan tepi sungai pepe (milik Tumenggung Mangkuyuda). Mangkunegara II (1796-1835) pindah dan menempati lokasi seperti yang sekarang.

Penelitian ini perlu dilakukan mengingat sejarah perkembamgan arsitektur di Indonesia yang dipengaruhi oleh/dari arsitektur Negara Eropa sebagai induknya.

\subsection{Aspek Arsitektur}

Aspek arsitektur adalah pandangan terhadap bagaimana terjadinya suatu wujud arsitektur. Arsitektur adalah lingkungan yang diciptakan manusia sendiri dari alam yang dikuasainya untuk memungkinkan kedudukan (kondisinya) dan sikap hidupnya dalam suasana yang diinginkan dan dalam status yang diharapkan (Yuswadi Sumaliyo). Arsitektur adalah pandangan terhadap suatu bangunan, dimana arsitektur terbentuk karena ruang, bentuk/wujud dan bahan, dari ketiga aspek wujud arsitektur terbentuk. Sedangkan menurut Vitruvius ada tiga aspek yang harus disintesiskan dalam arsitektur yaitu: Utilitas (fungsi), Venustas (yang ada kaitanya dengan wujud) dan Firmitas (struktur dan bahan).

\subsubsection{Aspek Fisik Arsitektur}

\section{a. Tata bangunan}

Tata bangunan merupakan hasil konfigurasi bangunan-bangunan yang saling dihubungkan satu dengan lainnya serta diorganisir sehingga membentuk pola-pola yang saling berkaitan (DK Cing,2007)

\section{b. Orientasi bangunan}

Orientasi (orient) menunjukan arah bangunan menghadap /menuju ke suatu arah tertentu, misalnya bangunan menghadap arah Timur atau bangunan menghadap arah halaman yang luas (DK Cing,2007).

\section{c. Denah Bangunan}

Denah menggambarkan layout dari susunan ruang. Denah terdiri dari satu ruang atau lebih yang susunannya dapat mengelompok, berdampingan atau berjajar memanjang (linier).

\section{d. Atap Bangunan}

Atap sebagai pelindung atau perisai yang menangkis radiasi panas dari matahari, pelindung pencurahan hujan dan hembusan angin. Atap terdiri dari tiga unsur utama, yaitu penutup atap, konstruksi penumpu penutup atap dan langit-langit (Marc Antoine L).

\section{e. Sistem Struktur Bangunan}

Sistem struktur suatu keseluruhan yang komplek dan terorganisir yang merupakan hasil dari penggabungan unsur atau bagian yang membentuk suatu kesatuan yang 
kompleks. Struktur atau sistem struktur merupakan susunan fisik dari bermacam komponen yang terkait satu dengan yang lain dan dirancang serta dibangun untuk berfungsi sebagai kesatuan secara keseluruhan, dan mampu segala macam beban untuk menyalurkan ke dalam tanah. Sebagai contoh sistem struktur yang sederhana misalnya, adanya pondasi, kolom, balok dan lantai (Sidharta, 2003).

\subsection{Arsitektur Belanda}

Belanda termasuk negara kecil di Eropa tetapi sejak abad 17 peranannya terhadap perkembangan ilmu pengetahuan, seni dan filosofi sangat menonjol. Pada abad 19 Belanda mengalami kemandegan dalam bidang arsitektur. Baru pada awal abad 20 Belanda bersama-sama dengan Rusia, Perancis dan Jerman menjadi pusat perhatian pada seni dan Arsitektur di Eropa (Handinoto, 1997) Kehadiran arsitek Belanda di Indonesia dimulai seorang Gothic Revivalist yang bernama Peter. JH Cuypers (1827-1921). dan mencapai puncaknya pada pengikut aliran Art Nouveau H.P. Berlage (1856-1934). Kemudian disusul pengikut - pengikutnya dari aliran Amsterdam Scholl dengan tokohnya seperti Michel de Kler .Terdapat pula aliran Nleuvte Kunst, aliran ini yang berkembang menjadi aliran arsitektur modern Belanda. Kebangkitan arsitektur di Belanda dari tahun 1865 - 1915 sebagai akibat dari kemajuan industri yang berlanjut di Eropa.Arsitektur Belanda banyak diilhami dari wujud arsitektur di luar Belanda, seperti bentuk klasik, bentuk ini kemudian di bawa bangsa Belanda ke negeri jajahan (koloni). Rancangan arsitek Belanda di daerah jajahan disamping pengetrapan elemen arsitektur Neo- klasik seperti ; kolom, dormer, gable, pintu-jendela, sistem teknologi, bahan dan sistem peruangan dari arsitektur modern.

\subsection{Arsitektur Kolonial Belanda di Indonesia}

Arsitektur kolonial adalah arsitektur cangkokan dari negeri induknya Eropa ke daerah koloni. Arsitektur kolonial Belanda adalah arsitektur Belanda yang dikembangkan di Indonesia, selama Indonesia masih dalam kekuasaan Belanda sekitar awal abad 17 sampai tahun 1942 (Sidharta, 1987). Yulianto Sumalio menyebutkan arsitektur kolonial Belanda di Indonesia adalah fenomena budaya yang unik, tidak terdapat di lain tempat, juga pada negara-negara bekas koloni, karena arsitektur kolonial Belanda di Indonesia terdapat pencampuran budaya penjajah dengan budaya Indonesia. seperti benteng Vastenburg, Bank Indonesia di Surakarta dan masih banyak lagi termasuk bangunan yang ada di Karaton Surakarta dan Puri Mangkunegaran.. Helen Jessup (1988 ; 44), dalam Handinoto sebagai berikut Gaya arsitektur Hindia Belanda abad 19 yang dipelopori oleh Daendels tersebut kemudian terkenal dengan sebutan The Dutch Colonial villa

\subsubsection{Perkembangan Arsitektur Kolonial Belanda di Indonesia}

Pada Tahun 1920 muncul gerakan pembaharuan dalam arsitektur, yang kemudian mempengaruhi arsitektur kolonial Belanda di Indonesia. Pada masa ini memunculkan gaya yang disebut eklectisme (dengan mengambil dan memilih bermacam-macam detail dari langgam masa lalu yang menarik dan mengombinasikan menjadi satu kesatuan). Para arsitek Belanda memberikan khas pada arsitektur Hindia-Belanda dengan menggunakan arsitektur tradisional Indonesia sebagai sumbernya.

Arsitektur di Hindia - Belanda pada permulaan abad ke 19 di perkenalkan Empire-style (Gaya kemaharajaan). Empire style diterjemahkan dan dibentuk secara bebas menjadi gaya pembangunan di Hindia-Belanda.

\subsubsection{Bentuk denah arsitektur kolonial Belanda}

Selama abad 17 gaya arsitektur kolonial Belanda berkembang pada rumah-rumah orang Belanda di seluruh Hindia Belanda Menurut Palladia dan Scamazzi, konsep pembentuk ruang berdasarkan fungsi, yang dibentuk dengan ruang-ruang yang simetris,. Kemudian menurut Sidharta dalam "The Dutch Architectural Heritage In Indonesia terdiri dari banyak ruang. 


\subsubsection{Orientasi Bangunan Arsitektur Kolonial Belanda}

Rumah tinggal orang kolonial Belanda terdapat bangunan utama/induk, menghadap ke halaman yang luas, dengan dikelilingi bangunan penunjang menghadap arah bangunan utama Bangunan rumah tinggal kolonial Belanda pada jaman VOC tahun 1618-an yaitu rumah-rumah di. dalam benteng berjajar menghadap arah dalam.

\subsubsection{Bentuk Atap Arsitektur Kolonial Belanda}

Penggunaan elemen atap pada arsitektur kolonial terdapat bentuk atap limasan dan pelana, dengan sudut kemiringan sekitar tiga puluh derajat atau lebih Pada atap terdapat pula elemen gable, dormer dan menara (tower). Penggunaan elemen pada atap. Seperti disebutkan Gothfried dalam Hadinoto yaitu : penggunaan gable pada tampak depan bangunan." The gable end of a building is the triangular portion of a building's end wall with a sloping roof Gable may be either of the some material as the rest of the wall or of contrasting material, texture or appearance".

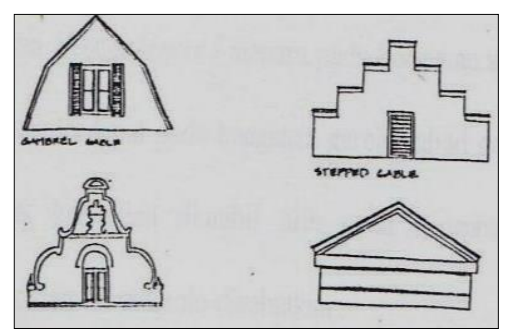

Gambar 1. Bentuk Atap Arsitektur Kolonial Belanda

\subsubsection{Penggunan Dormer pada Bangunan Kolonial Belanda}

Penggunaan dormer pada bangunan arsitektur kolonial Belanda sebagai usaha untuk pengatasan iklim tropis, dormer sebagai jendela yang diletakan pada sisi-sisi atap. Seperti di jelaskan oleh Gothfried dalam Handinoto sebagai berikut: "a Dormer is a window or other opening, such as louver, projected through a sloping roof and provided with its own roof. The dormer frame is usually placed vertically on the rafters of the main roof.

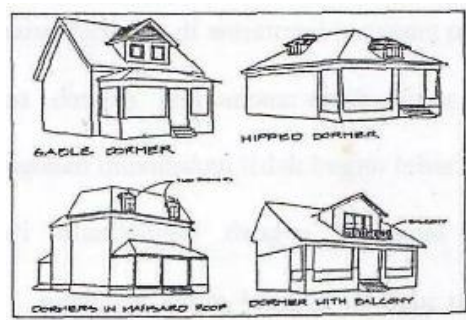

Gambar 2. Dormer

\subsubsection{Penggunaan Balustrade}

Pada atap dan penggunan konsol (penyangga atap trilisan). Selain mengetrapkan elemen menara (tower), dormer dan geble juga terdapat balustrade. Elemenelemen ini terus menjadi model dan terus dikembangkan pada bangunan colonial Belanda antara tahun 1900 an. Namun yang paling menonjol adalah usaha penyesuaian bangunan terhadap iklim tropis basah di Indonesia, penyesuaian tersebut di antisipasi terutama pada:

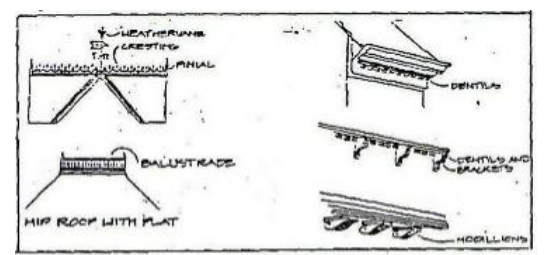

Gambar 3. Balustrade

\subsection{Arsitektur Indisch}

Pengembangan suatu bentuk arsitektur yang berciri khas Indisch, dimana tradisi arsitektur traditional Indonesia akan memperoleh tempat yang layak . Tanda - tanda ingin memberi ciri khas bentuk arsitektur Indisch ini adalah karya Jr. Henri Madaine Pont pada tahun 1918 yaitu,

\section{Teknologi Konstruksi Bangunan Kolonial Belanda}

Konstruksi bangunan kolonial Belanda sangat berbeda dengan arsitektur tradisional di Indonesia Arsitektur kolonial Belanda menggunakan sistem penyangga campuran, masa awal ini membuat bangunan dengan struktur dinding padat yang terbuat dari batubata. Jenis batu- bata ini merupakan batu bata khusus, yaitu bata yang keras dan awet, disebut "Winker" yang di datangkan dari negeri Belanda, dengan ketebalan tembok dua batu atau $60 \mathrm{~cm}$ bahkan ada yang lebih. Untuk 
tiang luar pada serambi /emperan, menggunakan kolom/ tiang dari pasangan batu bata, ada yang dari bahan besi tuang bentuk bulat gaya Neo-klasik. Arsitektur kolonial belanda mulai menggunakan bahan dari kaca yang memungkinkan perembesan cahaya lewat dinding kaca.Rangka atap arsitektur kolonial Belanda menggunakan sistem kuda-kuda dari bahan kayu dan dari besi/ baja.

\section{METODE}

\subsection{Lokasi Penelitan}

Penelitian ini dilakukan di lingkungan Karaton Puri Mangkunegaran Surakarta dengan obyek bangunan Pendopo Puri Mangkunegaran terkait dengan aspek-aspek arsitektur nya

\subsection{Sumber Data}

Jenis sumber data dalam penelitian ini yaitu data non fisik yang terkait dengan sejarah berdirinya Puri Mangkunegran, sumber data (survey) dari perpustakaan yang ada di Puri Mangkunegran, data fisik mengadakan opservasi pengamatan, pengukuran dan sketsa, serta pengambilan gambar foto fisik pada bangunan Pendopo

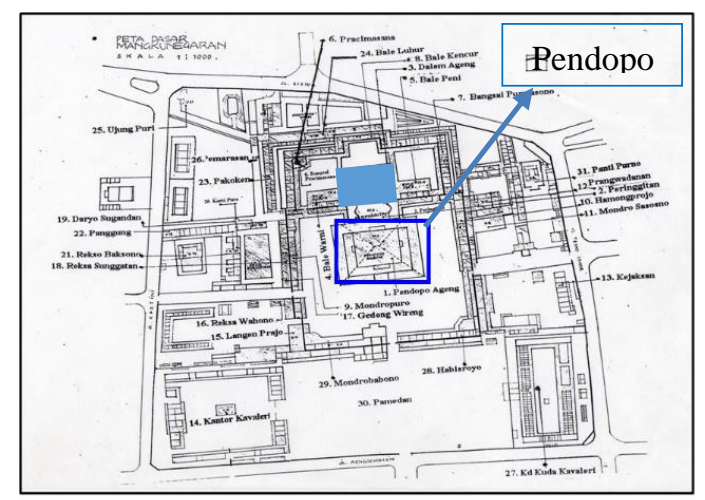

Gambar 4. Situasi Puri Mangkunegaran Sumber: Perpustakaan Puri Mangkunegaran

\subsection{Teknik Analisis}

Teknik analisis dalam penelitian dilaksanakan dengan analisis diskriptif kwalitatif dengan cara mengurai dengan media gambar pada data yang dikumpulkan berupa kata-kata tertulis atau lisan, gambar-gambar dan bukan angkaangka dikaji dengan teori (Lexy J. Moleong, $1993: 5,17$ dan 27

\section{HASIL DAN PEMBAHASAN}

Aspek-aspek arsitektur Kolonial Belanda pada bangunan Pendopo

\subsection{Tata bangunan}

Tata bangunan rumah tradisional Jawa terdiri dari bangunan utama(inti) dan bangunan penunjang dengan susunan dari depan; pendapa, peringgitan, dalem (rumah belakang). Di belakang dan kanan kiri dalem terdapat gandhok kiwo (kiri), gandhok tengen (kanan). Tata letak Pendapa Ageng terletak di paling depan atau depan Peringgitan. Lelak Pendapa di daerah umum. Pendapa Ageng terletak ditengah (centre) terhadap bangunan Mandrapura, Bale Warni, .Bale Peni Hainongpraja, Mandiasana dan Habisraya (Fisik Tata letak Pendopo Ageng mengikuti aspek fisik rumah tradisional Jawa).

\subsection{Orientasi}

Bangunan utama menghadap ke arah halaman untuk bangunan penunjang bangunan bangunan menghadap ke dalam ke arah bangunan utama. Pada rumah tradisional Jawa orientasi ke arah sumbu Utara-Selatan. Orientasi Pendapa Ageng menghadap arah Selatan mengikuti arah rumah tradisional Jawa, atau mengikuti arah Karaion Kasunanan. (Aspek arsitektur Jawa)

\subsection{Bentuk denah pendodpo}

Bentuk Denah simetris satu ruang. ukuran $51,60 \mathrm{~m} \mathrm{x} \quad 62,34 \mathrm{~m}$. Denah bangunan tanpa dinding. (Denah Pendapa Ageng rumah tradisional Jawa).

- Bentuk denah empat sisi ukuran 51,60 x $62,34 \mathrm{~m}$.

- Terdapat lantai utama lebih tinggi dari lantai emperean

- Denah tempat sisi konsep pat-ju-pat (4 mata angin), tedapat makna simbol.

- Terdapat penambahan ruang emperan (terluar) pada keliling denah/bangunan (Aspek arsitektur kolonial) 


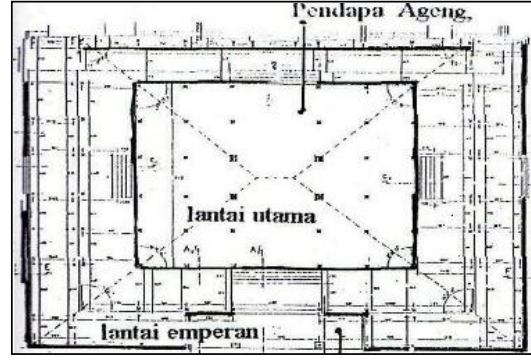

Gambar 5. Denah Pendopo

Sumber: Perpustakaan Puri Mangkunegaran

- Bentuk denah empat sisi ukuran 51,60 x $62,34 \mathrm{~m}$.

- Terdapat lantai utama lebih tinggi dari lantai emperean.

\subsection{Bentuk atap}

Bentuk atap pendopo rumah traditional Jawa, Pendapo ber atap joglo. Joglo merupakan bentuk atap traditional Jawa yang paling sempuma, biasanya hanya kaum bangsawan yang memiliki. (Sejarah dan Antropologi, Bunga Rampai Adat Istiadat 1977) Dari bentuk-bentuk joglo yang ada Joglo Hageng (Joglo Besar), joglo Pendapa Ageng sama dengan Joglo Pangrawit yang ditambah dua lapis atap " peningrat" dan "emperan", dengan demikian atap pendapa menjadi besar (Hageng). Atap Pendapa Ageng bentuk joglo, atap traditional Jawa, namun Pada atap Pendapa terdapat elemen dormer pada lapis atap brujung 6 buah dan elemen gable pada atap Kuncungan pada daerah pintu masuk memiliki lima lapis yaitu: Lapis brunjung, penanggap, penitih, peningrat dan atap emper (Elemen dormer dan gable pengaruh fisik arsitektur kolonial Belanda).

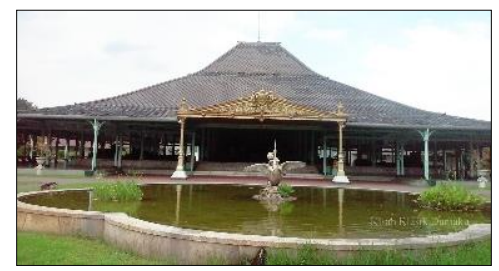

Gambar 6. Tampak Depan

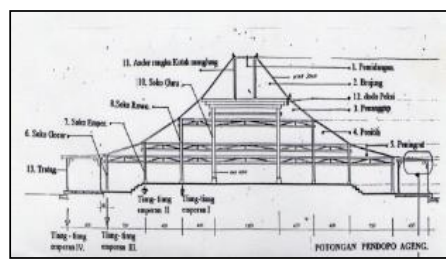

Gambar 7. Tampak dan Potongan Sumber: Perpustakaan Puri Mangkunegaran

\subsection{Struktur kolom (tiang)}

Tiang- Tiang Penyangga Pada Pendapa Ageng. Pendapa ageng mempunyai 4 Saka Guru, dimana tiang penyangga I; berjumlah 12 buah, tiang penyangga II; berjumlah 20 buah, tiang penyangga III; berjumlah 28 buah, dan tiang pada emperan berjumlah 46 buah.. Hal ini mengingat saka guru adalah penyangga utama beban atap. Pimcak atap dari Pendapa Ageng ini tingginya 17 meter dari lantai saka guru (Tiang utama) berjumlah 4 buah, dengan penampang 40 x $40 \mathrm{~cm}$ dan tinggi 10,50 M.

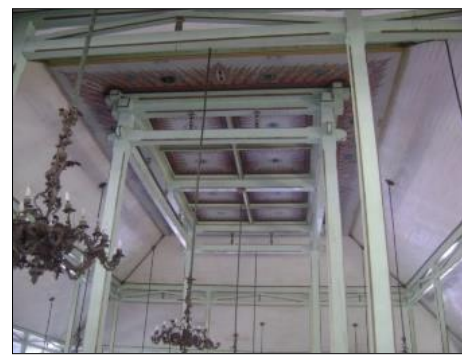

Gambar 8. Saka Guru

\subsection{Emperan ke IV}

Posisi paling luar merupakan emperan tambahan yang atapnya ticlak didukung oleh tiang-tiang dari kayu tetapi didukung dari besi tuang dengan diameter penampang $20 \mathrm{~cm}$ dan tinggi 4,00 meter. Seluruh konstruksi emperan dart besi tuang ( Konstruksi arsitektur kolonial Belanda konstrukksi.( elemen kolonial) Soko guru.

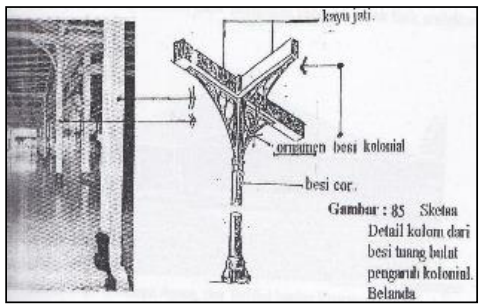

Gambar 9. Tiang besi tuang

Sumber : Perpustakaan Puri Mangkunegaran

\subsection{Saka Emper (Tiang emperan II)}

Saka emper 26 × $26 \mathrm{~cm}$ (tiang emperan bagian II) berjumlah 20. Tinggi 4m. Merupakan konstruksi tradisional Jawa. Terdapat kayu pengikat antara tiang dengan tiang, yang berbentuk segi tiga sebagai upaya penguat atau kestabilan konstruksi. (elemen Arsitektur kolonial). 


\subsection{Rong - Rongan / Rangka Atap}

Rangka atap/rong-rongan Pendapa Ageng dengan sistem rangka kayu, terdiri dari saka guru, sunduk, sunduk kill, pengeret, molo, santen, ganja, dudur dan usuk. Rong - rongan dengan sistem tumpang sari. Rangka atap / rong-rongan bangunan Pendapa Ageng dengan sistem tumpang sari, sistem sambungan purus dan pasak. Merupakan konstruksi tahan gempa (konstruksi ruamh tradisional Jawa.

\subsection{Saka Goco}

Saka goco merupakan tiang emperan ke III yang mengelilingi emperan $\mathrm{n}$ inasing-masing mempunyai penampang $20 \times 20 \mathrm{~cm}$, tinggi 4 $\mathrm{m}$. Berjumlah 28 buah. Beifungsi untuk menahan atap emper HI dan atap tratag, merupakan sistem konstruksi tradisional Jawa Kedudukan saka goco berdampingan dengan tiang besi dan pada saka goco terdapat elemen kayu berbentuk dasar segi tiga sebagai usnha penguat benteng lebar $6,00 \mathrm{~m}$ berfungsi untuk kestabilan konstruksi (Aspek lisik konstruksi arsitektur kolonial Belanda).

\subsection{Tiang tratag}

Tiang tratag merupakan tiang emperan paling luar, dibuat dari besi tuang berpenumpang 20 $\mathrm{cm}$, tinggi $4 \mathrm{~m}$, berjumlah 4 buah. Tiang besi tuang menipakan konstnlksi rangka, pengaruh dari aspek fisik konstnlksi arsitektur kolonial Belanda Konstruksi ini sebagai upaya mengatasi bentang yang lebar mencapai bentang 5,70 $\mathrm{m}$ dan ada yaug bentang 8,60. Serta untuk mengatasi kemiringan atap yang lantai dibawah sudut 10 derajat, karena untuk penutup atap digunakan bahan seng agar ketinggian linsplank atap dapat maksimal. (ketinggian lisplank mencapai 4,20 $\mathrm{cm}$ dari lantai tritisa.

\subsection{Tiang Besi Tuang pada Kuncungan}

Tiang besi yang berjumlah dua buah berfungsi menahan gable pada kuncungan, sebagai usaha pengatasan bentang yang lebar $(6,00 \mathrm{~m})$. Tiang besi dengan gaya Neo-klasik, pada gable terdapat ornamen dengan motif daun dan muka wanita frontal, bahan dari tembaga warna kuning emas. Kesemuanya ini merupakan usaha untuk memberi kesan, megah, agung, awet dan indah. Tiang besi dan gable merupakan pengaruh aspek flsik arsitektur koloniai Belanda.

\subsection{Lantai Pendop Ageng}

Lantai Pendapa telah mengalami pergantian di masa pemerintahan Mangkunegaran Vlt (1916 - 1944). Lantai diganti dengan marner dari Italia, dengan tujuan selain kelihatan bersih, tahan lama, mudah dirawat dan memberi kesan wibawa(Aspek arsitektur kolonial Belanda).

\subsection{Detail hubungan atap lama dengan atap baru}

Atap lama dengan atap baru (atap tambahan) terdapat konstuksi balustrade hubungan atap sirap dan atap seng

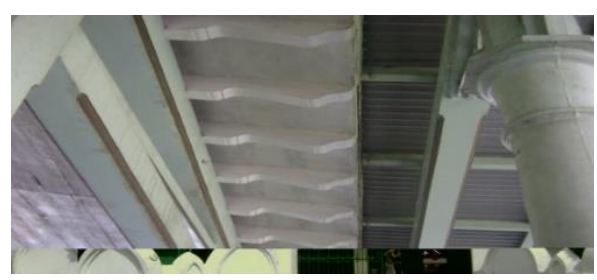

Gambar 10. Balustrade

\section{KESIMPILAN}

Temuan Aspek Arsitekutr pada Pendopo Puri Mangkunegaran terdapat elemen dormer pada lapisan atap brujung di empat sisi (6 buah) berfungsi untuk ventilias udara didalam sambungan atap. Terdapat Gable pada atap pintu masuk, tiang besi tuangserta lantai marmer ( elemen arsitektur colonial).

Tabel 1. Tenuan Aspek Arsitektur Kolonial Belanda

\begin{tabular}{clcc}
\hline No & Aspek Fisik & $\begin{array}{c}\text { Arsitektur } \\
\text { Tradision } \\
\text { al Jawa }\end{array}$ & $\begin{array}{c}\text { Arsitektur } \\
\text { kolonial } \\
\text { Belanda }\end{array}$ \\
\hline $\mathbf{1}$ & $\begin{array}{l}\text { Tata Bangunan } \\
\text { inti, dalem, } \\
\text { pringgitan dan } \\
\text { pendopo }\end{array}$ & $\sqrt{ }$ & - \\
\hline $\mathbf{2}$ & $\begin{array}{l}\text { Denah terdapat } \\
\text { penambahan } \\
\text { lantai pada sisi } \\
\text { luar keliling } \\
\text { bangunan }\end{array}$ & $\sqrt{ }$ & $\sqrt{ }$ \\
\hline $\mathbf{3}$ & $\begin{array}{l}\text { Orientasi } \\
\text { bangunan } \\
\text { pendopo } \\
\text { Arah selatan }\end{array}$ & $\sqrt{ }$ & \\
\hline
\end{tabular}


Samsudi, Agung Kumoro W, Dyah Susilowati P.P, Anita Dianingrum, Aspek-aspek Arsitektur Kolonial....

\begin{tabular}{|c|c|c|c|}
\hline 4 & $\begin{array}{l}\text { Bentuk atap } \\
\text { Joglo terdapat } 4 \\
\text { lapis, terdapat } \\
\text { elemen, dormen } \\
\text { pada } 4 \text { sisi atap }\end{array}$ & $\sqrt{ }$ & $\sqrt{ }$ \\
\hline 5 & $\begin{array}{l}\text { Pada sisi lantai } \\
\text { tepi terdapat } \\
\text { kolom besi tuang }\end{array}$ & - & $\sqrt{ }$ \\
\hline 6 & $\begin{array}{l}\text { Pada canopy } \\
\text { terdapat gable } \\
\text { bahan tembaga } \\
\text { warna kuning } \\
\text { keemasan }\end{array}$ & - & $\sqrt{ }$ \\
\hline 7 & $\begin{array}{l}\text { Lantai utama } \\
\text { lantai } \\
\text { marmer,lantai } \\
\text { emperan, } \\
\text { berlantai tegel } \\
\text { kembang hijau } \\
\text { bermotif }\end{array}$ & - & $\sqrt{ }$ \\
\hline 8 & $\begin{array}{l}\text { Detail hubungan } \\
\text { atap lama dengan } \\
\text { atap seng }\end{array}$ & - & $\sqrt{ }$ \\
\hline
\end{tabular}

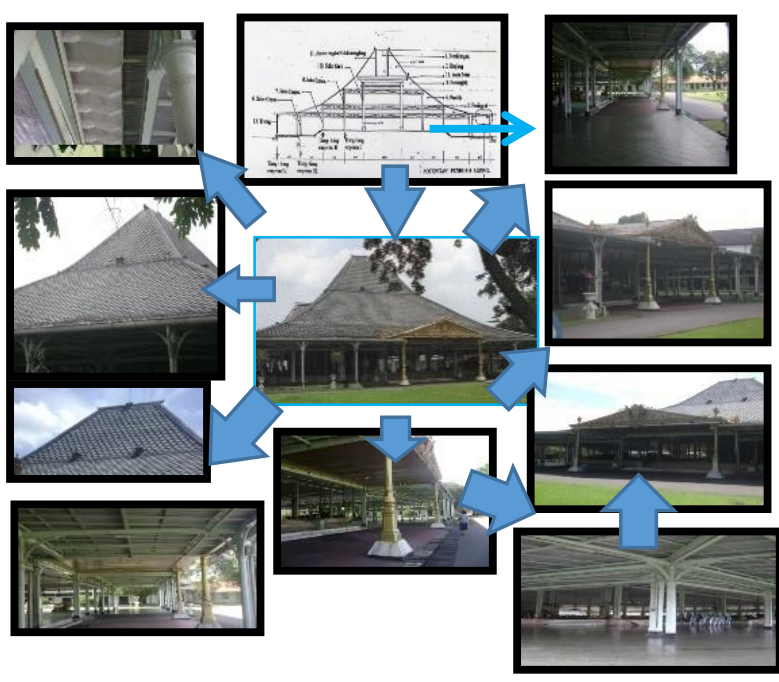

Gambar 11. Hasil Temuan

\section{UCAPAN TERIMAKASIH}

Ucapan terima kasih kepada semua pihak yang telah membantu dalam penelitian ini, sehingga penelitian ini dapat selesai.

\section{REFERENSI}

Akihary, Huib, 1988, Architectuur en Stedebouw in Indonesie 1870 - 1970, Rijksdienst voor de Monumenten zong Zeist

Budihardjo, Eko, 1996, Jati Diri Arsitektur Indonesia, FT Alumni, Bandung

BappedaTingkat I dan Fakultas Teknik Universitas Diponegoro Semarang, 1987, Penelitian Konsertasi Lingkungan \& Bangunan Kuno Bersejarah Di Surakarta

Dakung, Sugiarto 1981/1982, Arsitektur Tradisional Daerah Istimewa Yogyakarta, Departemen pendidikan Dan Kebudayaan

DK Ching, Francis, In Paulus Hanoto Ajie, 1985, Arsitektur : Bentuk-Ruang \& Susunannya, Erlangga, Jakarta

Frick, Heinz, 1997, Pola Struktur dan Teknik Bangunan di Indonesia, University Press Soegiyapranata, Yogyakarta

Gedenk Bode Der Gemeente Semarang, 1906/l931,Uitgegeven tergelegen beid van bet, Vijf En Twintig Jarig Bestaan Der Gemeenten. Uitgegeven in Opdracht Der Gemeente Door De N. V Dagblad De Locomotif

Haris, Cyil M, 1977, Ilustrated Dictinary of Architecture, Company, New York

Handinoto, 1996, Perkembangan Kota dan Arsitektur Kolonial Belanda di Surabaya" 1870 - 1940, Lembaga Penelitian dan Pengabdian Masyarakat Universitas Kristen Petra Surabaya dan Penerbit Andi, Yogyakarta

Hidding, Mulia TSG, KAH, 1977, Ensiklopedia Indonesia, NV Pusat Penelitian Sejarah dan Budaya Jakarta

Hadi, Sutrisno, 1981, Metodologi Research, Yayasan Penerbitan Fakultas Psikologi Universitas Gajah Mada Yogyakarta

Hakim, Rustam, 1987, Unsur Perancangan Dalam Arsitektur Lansekap, PT Bina Aksara, Jakarta

Moleong, Lexy J. 1993, Metodologi Penelitian Kualitatif, Remaja Rotdakatya, Bandung.

Mangunwidjaya, YB, 1981, Pasal-Pasal Pengantar Fisika Bangunan, PT Gramedia Jakarta 
Panitia,1988, Pembangunan Kembali Bangunan Inti Karaton Surakarta, Jakarta

Rapoport, Amos, 1969, House Form and Culture " Foundations of Cultural Geography Series, University of Wisconsin- Milwaukee United States of

Sidharta, tanpapa tahun, Seni Bangunan Belanda Tropis di Hindia Belanda Terjemahan dari buku J.F.Van Hoy, tema De Tropisch Nederlandsche Bouwkunst in Indie 1946,

Sajid, RM, 1980, Babat Sala, Rekso Pustaka Mangkunegaran Solo

Sumalyo, Yulianto, 1995, Arsitektur Kolonial Belanda di Indonesia, Gadjah Mada University Press

Sutopo, HB, 1988, Pengantar Penelitian Kualitatif/Dasar-Dasar Teoritis dan Praktis, Pusat Penelitian Universitas Sebelas Maret Surakarta

Wiryomartono, A Bagoes P , 1995, Seni Bangunan dan Seni Bina Kota, di Indonesia, Kajian Mengenai Konsep, Struktur, dan Elemen Fisik Kota Sejak Peradaban Hindhu - Budha, Islam Hingga Sekarang, PT. Gramedia Pustaka Utama, Jakarta,

Wit, Wim de, 1983, The Amsterdam School Dutch Expressionist Architecture, 19151930, The Smit Press, London, England. 